\title{
Ionic Liquid-Facilitated Preparation of Lignocellulosic Composites
}

\author{
Brent Tisserat, ${ }^{1}$ Erik Larson, ${ }^{2}$ David Gray, ${ }^{2}$ Nathaniel Dexter, ${ }^{2}$ \\ Carl Meunier, ${ }^{2}$ Lena Moore, ${ }^{2}$ and Luke Haverhals ${ }^{2}$ \\ ${ }^{1}$ Functional Foods Research Unit, National Center for Agricultural Utilization Research, Agricultural Research Service, \\ United States Department of Agriculture, Peoria, IL 61604, USA \\ ${ }^{2}$ Mund-Lagowski Department of Chemistry and Biochemistry, Bradley University, Peoria, IL 61625, USA
}

Correspondence should be addressed to Brent Tisserat; brent.tisserat@ars.usda.gov

Received 6 February 2015; Revised 2 April 2015; Accepted 16 April 2015

Academic Editor: Saiful Islam

Copyright (c) 2015 Brent Tisserat et al. This is an open access article distributed under the Creative Commons Attribution License, which permits unrestricted use, distribution, and reproduction in any medium, provided the original work is properly cited.

\begin{abstract}
Lignocellulosic composites (LCs) were prepared by partially dissolving cotton along with steam exploded Aspen wood and burlap fabric reinforcements utilizing an ionic liquid (IL) solvent. Two methods of preparation were employed. In the first method, a controlled amount of IL was added to preassembled dry matrix of cotton and Aspen wood with a burlap weave reinforcement. In the second method, IL solvent, cotton, and Aspen wood were mixed to produce a thick paste matrix that was subsequently pressed into the burlap weave reinforcement. The IL-based solvent was removed via water soaking, and the flexural and tensile properties of the LCs were examined. In this study, the matrix paste method produced a superior LC. Variables such as processing time (IL interaction time) and fabric weaves were found to influence the mechanical properties of the LCs. Although significant process optimization can still be realized, the mechanical properties of several of the LCs fabricated in this study were comparable to injection molded test specimens of neat high density polyethylene or neat polypropylene.
\end{abstract}

\section{Introduction}

There is an ever growing need to produce goods (e.g., fuels and consumer/industrial items) without petroleum [1-5]. Alternative sources of energy and feedstocks for materials and chemicals utilizing renewable resources are sought in order to lessen the dependence on petroleum, improve product performance, minimize environmental impact, and reduce costs [2]. Biofuels may be obtained by processing and fermenting lignocellulosic materials (i.e., waste wood, corn stover, and sugarcane bagasse).

About $8 \%$ of total petroleum products (i.e., crude oil and natural gas) are utilized in the manufacture of plastics $[6$, 7]. Bioplastic alternatives, whether biodegradable (polylactic acid or polyhydroxyalkanoates) or nondegradable (biopolyethylene or biopolyethylene terephthalate), are obtained by processing renewable resources into monomers [1]. Unfortunately, processing biosubstrates into monomers is often too energy intensive to be cost competitive with petroleum-based monomers. An alternative is to directly incorporate biomaterials with thermoplastics to produce composites and thereby displace some of the plastics produced from bio- or oilderived monomers. Lignocellulosic biomass from a variety of sources is routinely blended in percentages up to $50 \%$ with thermoplastics to produce biocomposites (i.e., wood plastic composites (WPCs)) [8-12]. While WPCs have certain economic and sustainability advantages, they also have inherent limitations such as the incompatibility issues occurring between the matrix (polyolefins) and the filler/reinforcement (lignocellulosic material). WPCs are difficult to recycle and, of course, still utilize substantial amounts of thermoplastics which continue to pose environmental problems $[6,13,14]$.

Plastics are typically defined as synthetic materials made from a wide range of organic polymers, such as polyethylene, polypropylene, and nylon, that can be molded into shapes while being soft and then set into a rigid or slightly elastic forms $[7,10]$. However, the term plastics can also be defined more generally as materials that can be easily shaped 
or molded without regard to any thermoplastic reference. The focus of our research is to create biocomposites that are wholly composed of natural substrates but that are moldable. Furthermore, our goal is to generate composites that exhibit mechanical properties on par with petroleumbased thermoplastics. Other considerations are to produce these composites at a comparable cost to thermoplastics and employ sustainable processes that have a smaller environmental footprint than thermoplastics. In so far as this is possible, several intriguing synergies are apparent. First, inherit incompatibilities between natural and synthetic substrates may be avoided. Second, biocomposites composed of the same or similar materials should be easier to recycle (even becoming compostable) $[15,16]$. Third, biocomposites may exhibit unique property combinations (i.e., strength, flexibility, and water transport) which are not easily obtained from synthetic polymers.

The concept of developing all-cellulose composites (ACCs), in which both the matrix and the reinforcement agents are cellulose-based, has been demonstrated [15-22]. Speaking broadly, ACCs are prepared by introducing a cellulose matrix around a fibrous (cellulosic) reinforcement material. Cellulose is the most abundant biopolymer in nature with an estimated production of $1.5 \times 10^{12}$ tons/year and has mechanical properties (tensile strength: 13-17 GPa; tensile modulus: $138 \mathrm{GPa}$; density of $1.58 \mathrm{~g} / \mathrm{cm}^{3}$ ) on par or exceeding many of the common synthetic polymers $[15,16]$. To create ACCs, a wet process is necessary, for example, dissolving cellulose in $\mathrm{N}, \mathrm{N}$-dimethylacetamide containing $\mathrm{LiCl}$ followed by its resolidification in the presence of reinforcement material [15]. Ionic liquids (ILs) such as 1-ethyl-3-methylimidazolium acetate (EMIMAc) have also been utilized to prepare ACCs [23]. ILs may also be used to prepare composites using other biopolymers such as silk [21]. Although IL is currently expensive, it has certain advantages over other cellulose dissolving solvents such as being recyclable, relatively environmentally friendly, and very effective [19, 21-23]. In addition, finding large-scale uses for IL will undoubtedly reduce its manufacturing costs. In this work, we sought to fabricate complex, moldable composites composed primarily of lignocellulosic materials utilizing IL as the cellulose solvent. Unlike in other studies where highly refined cellulose materials were employed, we are interested in employing lower cost lignocellulosic ingredients with minimal processing to generate lignocellulosic composites (LCs). Wood, for example, is a composite tissue composed of cellulose and hemicellulose with lignin acting as the network fiber binding carbohydrate components into compact structures [2]. It is difficult to dissolve wood with conventional solvents because of the intricate relationship between lignin and polysaccharide constituents. Much interest exists in separating the lignin from the carbohydrates to manufacture biofuels and chemical feedstocks [24-28].

This report explores different approaches to adequately mix biomaterials and IL solvents to yield LCs. The influence of solvent exposure time (i.e., the time IL interfaced with the LC components) and the effect of employing different reinforcement types and weaves on the LC mechanical properties were explored. We further compared the mechanical properties of the LCs generated specimen bars to that of injection molded bars composed of neat high density polyethylene (HDPE) or neat polypropylene (PP). This was done to determine if the LCs mechanical properties were comparable to thermoplastic resins. The cost of the unprocessed raw materials utilized in the LCs, cotton, \$0.58-0.69/lb, Aspen wood fiber, $\$ 0.12-0.25 / \mathrm{lb}$, and Jute burlap fibers, $\$ 0.14-0.25 / \mathrm{lb}$ (http://www.alibaba.com/), suggests these LCs (\$0.35-0.40/lb) are cost competitive with thermoplastics (i.e., HDPE (\$0.52-0.70/lb) and PP (\$0.65-0.75/lb)) for use in a variety of applications (http://www.plasticstoday.com/).

\section{Material Processing and Experimental Methods}

2.1. Chemicals and Materials. The IL, EMIMAc (>98\% purity), was obtained from IoLiTec Inc., Tuscaloosa, AL. Acetonitrile (ACN) ( $\geq 99.5 \%$ purity) was obtained from SigmaAldrich, St. Louis, MO. Reagents were used as received without any additional purification or modification.

Nonabsorbent (nonsterile/bleached) cotton (100\% cotton) was obtained from U.S. Cotton Co., Lachine, Canada. Aspen steam exploded wood (SEW) was provided by USDAForest Service Southern Research Station, Pineville, LA. Aspen wood chips were soaked in water for $16 \mathrm{hr}$ and then they were subjected to temperature of $190^{\circ} \mathrm{C}$ and pressure of 1.3 $\mathrm{MPa}$ for $5 \mathrm{~min}$ followed by the rapid release of pressure. Reinforcement fabrics employed were obtained from $23^{\prime \prime} \times$ $40^{\prime \prime}$ burlap bags, (ULine, Chicago, IL), burlap ribbons (Hobby Lobby, Oklahoma City, OK), and cotton canvas (DMC Corp., Kearny, NJ) (Table 1). The chemical composition of materials used in this study were cotton ( $94 \%$ cellulose), Aspen wood (57\% cellulose, 20\% hemicellulose, $16.3 \%$ lignin), and jute fiber (64-65\% cellulose, 20-25\% hemicellulose, 10-15\% lignin) (http://textilefashionstudy.com/; http://www .wikipedia.org/). Materials were dried for $48 \mathrm{hr}$ at $60^{\circ} \mathrm{C}$ prior to use.

2.2. Preparations. Two distinct procedures were conducted to obtain LCs. Table 1 summarizes the various treatments conducted in this research project.

2.2.1. Direct Application Method (DAM) of ILs. Dry matrix and reinforcement fiber weave were layered together (prior to adding solvent). Burlap fabric weaves were cut into $75 \mathrm{~mm} L \times$ $25 \mathrm{~mm} W$ pieces. Cotton and SEW were mixed in a blender prior to use. The matrix material $(0.8 \mathrm{~g})$ was sandwiched between two layers of burlap weave, each $\sim 0.45 \mathrm{~g}$ weight, in a rectangular silicone pan $(75 \mathrm{~mm} L \times 25 \mathrm{~mm} W \times 27 \mathrm{~mm} \mathrm{H})$ (Freshware Inc., Alhambra, CA). IL of $3.5 \mathrm{~mL}$ of $1 \mathrm{M}$ EMIMAc was applied to the surface of the burlap weave in a drop wise fashion and allowed to penetrate for $3 \mathrm{~min}$. The LC sandwich was turned over and a second application of $1.75 \mathrm{~mL}$ IL was administered to the burlap weave. A total of $5.25 \mathrm{~g}$ of IL was administered to the composite components. LCs, still in silicone trays, were microwave heated at 50 watts for 10 minutes in Ethos EX microwave Labstation (Milestone Inc., 
TABLE 1: Weight percentages in test formulations.

\begin{tabular}{lccc}
\hline Formulations* & Cotton & SEW & Burlap \\
\hline DAM & 10 & 50 & 40 \\
MPM: tight burlap weave & 10 & 45 & 45 \\
MPM: burlap bag weave & 10 & 45 & 45 \\
MPM: wide burlap weave & 10 & 52 & 38 \\
MPM: cotton weave & 15 & 65 & 20 \\
\hline
\end{tabular}

${ }^{*}$ DAM represents the method employing direct application of IL on dry LC components; MPM represents the method of incorporation of matrix materials with IL followed by reinforcement with burlap layers.

Shelton, CT) during which time the microwave was stopped to periodically flip the LC sandwich. The LC samples were pressed between stainless steel plates and incubated in an oven at either $60^{\circ} \mathrm{C}$ or $80^{\circ} \mathrm{C}$ for 30,90 , and 1200 minutes and then they were transferred to containers containing $2000 \mathrm{~mL}$ deionized distilled water to remove IL. Water was replaced every hour for 4 consecutive hours. Composites were transferred to paper towels and pressed between stainless steel sheets under 4.6 $\mathrm{MPa}$ for $16 \mathrm{hrs}$ until dried.

2.2.2. Matrix Paste Method (MPM) of ILs. To prepare the lignocellulose matrix, $0.2 \mathrm{~g}$ of cotton was immersed in $10 \mathrm{~g}$ solution of $1 \mathrm{~mol}$ EMIMAc: $1 \mathrm{~mol} \mathrm{ACN}$ in a rectangular silicone pan $(75 \mathrm{~mm} L \times 25 \mathrm{~mm} W \times 27 \mathrm{~mm} \mathrm{H})$. The mixture was exposed to microwave heating for $15 \mathrm{~s}$ at 250 watts and then stirred with a microscapula. This heating and stirring process was repeated three additional times in order to obtain a partially viscous cotton paste. Next, $1 \mathrm{~g}$ of SEW was added to the paste by stirring then microwaved for $1 \mathrm{~min}$ at 50 watts; this heating and stirring process was repeated once more. LCs were created by applying the matrix material evenly to the bottom of a second rectangular silicone pan and then pressing a $75 \mathrm{~mm} L \times 25 \mathrm{~mm} W$ piece of burlap bag fabric weave, weighing $\sim 0.5 \mathrm{~g}$, into the matrix; next a second layer of matrix was applied and an additional weave was applied followed by another layer of matrix. Silicone trays were incubated at $80^{\circ} \mathrm{C}$ for $1200 \mathrm{~min}$ and then transferred to trays containing deionized distilled water to remove IL. Water was replaced every hour for 4 consecutive hours at $25^{\circ} \mathrm{C}$. LCs were then transferred to paper towels and pressed between stainless steel sheets under $4.6 \mathrm{MPa}$ for $16 \mathrm{hrs}$ at $60^{\circ} \mathrm{C}$ until dried. In some experiments, different fabric weaves were substituted for the burlap bag weave (Table 2).

2.3. Mechanical Property Measurements. LCs were punched with a clicker press fitted with specimen cutting dies to obtain ASTM test specimen sample bars: ASTM D790 flexural testing bar $(12.7 \mathrm{~mm} W \times 63.5 \mathrm{~mm} L \times 1.5 \mathrm{~mm}$ thickness $)$ and ASTM D638 Type $\mathrm{V}$ tensile testing bar $(9.5 \mathrm{~W}$ mm grip area $\times$ $3.2 \mathrm{~mm}$ neck $\times 63.5 \mathrm{~mm} L \times 1.5 \mathrm{~mm}$ thickness $\times 7.6 \mathrm{~mm}$ gage $L$ ). The Type $\mathrm{V}$ bars were used for the tensile strength property tests. The flexural bars were used to evaluate flexural properties.

Cut, dry LCs were conditioned for approximately 240 hours at standard room temperature and humidity $\left(23^{\circ} \mathrm{C}\right.$ and $50 \% \mathrm{RH}$ ) prior to any test evaluations. ASTM D638
TABLE 2: Properties of reinforcement fabric weaves employed in LCs.

\begin{tabular}{lccc}
\hline Reinforcement types & $\begin{array}{c}\text { Strand } \\
\text { thickness } \\
(\mathrm{mm})\end{array}$ & $\begin{array}{c}\text { Openings } \\
\left(\# / \mathrm{cm}^{2}\right)\end{array}$ & $\begin{array}{c}\text { Opening } \\
\text { size } \\
\left(\mathrm{mm}^{2}\right)\end{array}$ \\
\hline Tight burlap weave & 0.5 & 23.3 & 1.5 \\
Burlap bag weave & 1 & 15.5 & 1 \\
Loose burlap weave & 0.5 & 7.8 & 6 \\
Cotton weave & 0.5 & 15.5 & 3.1 \\
\hline
\end{tabular}

Type $\mathrm{V}$ tensile bars were tested for tensile modulus $(E)$, tensile strength $\left(\sigma_{u}\right)$, and elongation at break $(\% \mathrm{El})$ using a universal testing machine (UTM) Instron Model 1122 (Instron Corporation, Norwood, MA). The speed of testing was $5 \mathrm{~mm} / \mathrm{min}$. Three-point flexural tests were carried out according to ASTM-D790 specification on the Instron UTM Model 1122 using flexural bars. The flexural tests were carried out using Procedure B with a crosshead rate of $13.5 \mathrm{~mm} / \mathrm{min}$. The flexural strength $\left(\sigma_{\mathrm{fm}}\right)$ and flexural modulus of elasticity $\left(E_{b}\right)$ were calculated. Five specimens of each formulation were tested. The average values and standard errors were reported. Comparisons of the mechanical properties of the LCs with commercial polyolefins were conducted through normalization processes. The two common polyolefins tested were HDPE and PP matrix using Petrothene LS 5300-00 and Pro-fax SB891 (Equistar Chemical LP, Houston, TX). The specific physical properties and method to prepare injection molded tensile and flexural bars have been previously described [11, 12]. A 30-ton molding machine (Model Engel ES 30, Engel Machinery Inc., York, PA) using an ASTM family mold to obtain HDPE or PP test bars. Set point temperatures $\left({ }^{\circ} \mathrm{C}\right)$ for the four zone injection molding barrel were feed $=160$, compression $=166$, metering $=177$, and nozzle $=191$. The mold temperature was $37^{\circ} \mathrm{C}$. Type $\mathrm{V}$ bars were used for the tensile strength property tests. The flexural bars ( $12.7 \mathrm{~mm} W \times 63.5 \mathrm{~mm} L \times 3.2 \mathrm{~mm}$ thickness) were used to evaluate flexural properties of the composites. Type $\mathrm{V}$ bars $(9.5 \mathrm{~mm} W$ grip area $\times 3.2 \mathrm{~mm}$ neck $\times 63.5 \mathrm{~mm} L \times$ $1.5 \mathrm{~mm}$ thickness) were used to evaluate tensile mechanical properties of the composites. The average $\sigma_{u}, E, \% \mathrm{El}, \sigma_{\mathrm{fm}}$, and $E_{b}$ values of HDPE were 21.5, 339, 105, 27.9, and 894, respectively. The average $\sigma_{u}, E, \% \mathrm{El}, \sigma_{\mathrm{fm}}$, and $E_{b}$ values of PP were $25.2,576,82.2,43.9$, and 1386 , respectively [11, 12].

\section{Results and Discussion}

3.1. Influence of Reaction Incubation Time. EMIMAc has been reported to dissolve $100 \mathrm{~g}$ microcrystalline cellulose per $\mathrm{kg}$ EMIMAc IL and $50 \mathrm{~g}$ maple wood flour per $\mathrm{kg}$ EMIMAc IL [27]. In contrast we employed $\sim 1.3 \mathrm{~g}$ cotton/SEW/burlap with $5.25 \mathrm{~g}$ of IL to obtain our LC. Our aim was to procure an LC with the minimum amount of IL to reduce cost and limit denaturation to fiber reinforcements. Very little is known concerning how to prepare LC with IL and lignocellulosic ingredients as employed in this study. Therefore, we initially sought to determine how long should the LC mixture incubate with the IL solution (i.e., $1 \mathrm{M}$ EMIMAc: $1 \mathrm{M}$ $\mathrm{ACN}$ ) to achieve adhesion among the ingredients (Figure 1). 


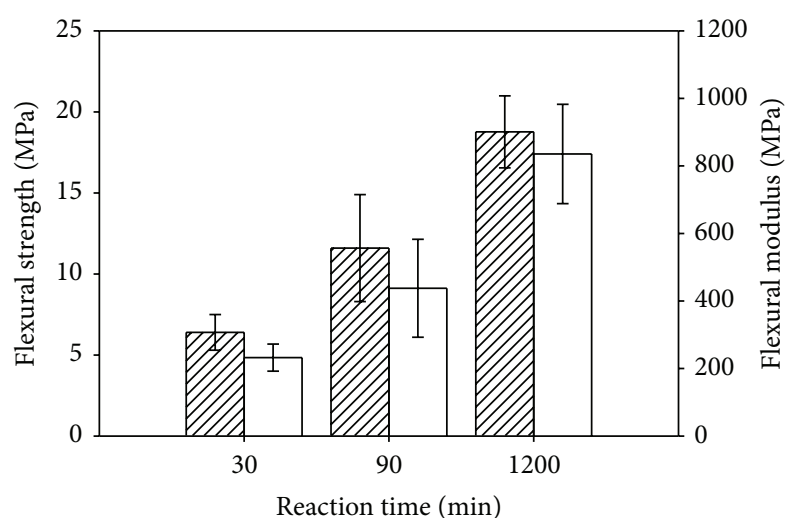

एس] Flexural strength

$\sqsubset$ Flexural modulus

FIGURE 1: Effect of varying the incubation times using EMIMAc IL on the flexural properties of LCs. All LCs were subjected to a $60^{\circ} \mathrm{C}$ incubation temperature and soaked in water for $4 \mathrm{hrs}$.

Increasing the incubation reaction time from $30 \mathrm{~min}$ to 90 min dramatically improved the flexural properties of the LC. LCs reacted for $30 \mathrm{~min}$ versus $90 \mathrm{~min}$ at $60^{\circ} \mathrm{C}$ exhibited $\sigma_{\mathrm{fm}}$ and $E_{b}$ values of $6.4 \pm 1.1$ and $232 \pm 40$ versus $11.6 \pm 3.3$ and $437 \pm 144$, respectively. Therefore the LC/IL mixture that incubated for $90 \mathrm{~min}$ at $60^{\circ} \mathrm{C}$ exhibited a 81 and $88 \%$ increase in $\sigma_{\mathrm{fm}}$ and $E_{b}$ values, respectively, compared to incubation for $30 \mathrm{~min}$ at $60^{\circ} \mathrm{C}$ (Figure 1). As shown in Figure 1, increasing the reaction time to 20 hours (i.e., $1200 \mathrm{~min}$ ) further improved the mechanical properties of the resulting LC. The $\sigma_{\mathrm{fm}}$ and $E_{b}$ values of the LC incubated for $1200 \mathrm{~min}$ at $60^{\circ} \mathrm{C}$ exhibited a $190 \%$ and $260 \%$ increase versus LC incubated for $30 \mathrm{~min}$ at $60^{\circ} \mathrm{C}$. Although the optimum incubation time was not determined, it is clear that the IL solution can continue to react with the LC components for a considerable time span. Additionally, it should be noted that the amount of adventitious water in the IL solvent and biomaterial substrates may slow the mobilization of biopolymer (e.g., cellulose) considerably and it will be addressed in future work [27-33].

The IL must be removed from the LC for hydrogen bonding networks to be established between matrix and fiber components. Several solvents have been employed to remove IL from the treated biomass materials [33]. When the LC is introduced into water, an immediate swelling of the LC occurs along with a brownish discoloration of water. We replaced the water every hour for four consecutive hours and noted that substantially less of the brownish material was exuded from the LC each time the water was replaced. In other studies, data not shown, leaving the LC overnight in water did not improve the mechanical properties of the LC versus using a 4 -hour soaking treatments. The influence of the soaking temperature was also examined using $25^{\circ} \mathrm{C}$ or $70^{\circ} \mathrm{C}$. In both cases, the LC swelled considerably in the water. Furthermore, increasing the soaking temperature from $25^{\circ} \mathrm{C}$ to $70^{\circ} \mathrm{C}$ did not improve the mechanical properties of the LCs. For example, LCs water soaked for $30 \mathrm{~min}$ at $70^{\circ} \mathrm{C}$ exhibited $\sigma_{\mathrm{fm}}$ and $E_{b}$ values that were $10 \%$ less than LCs water
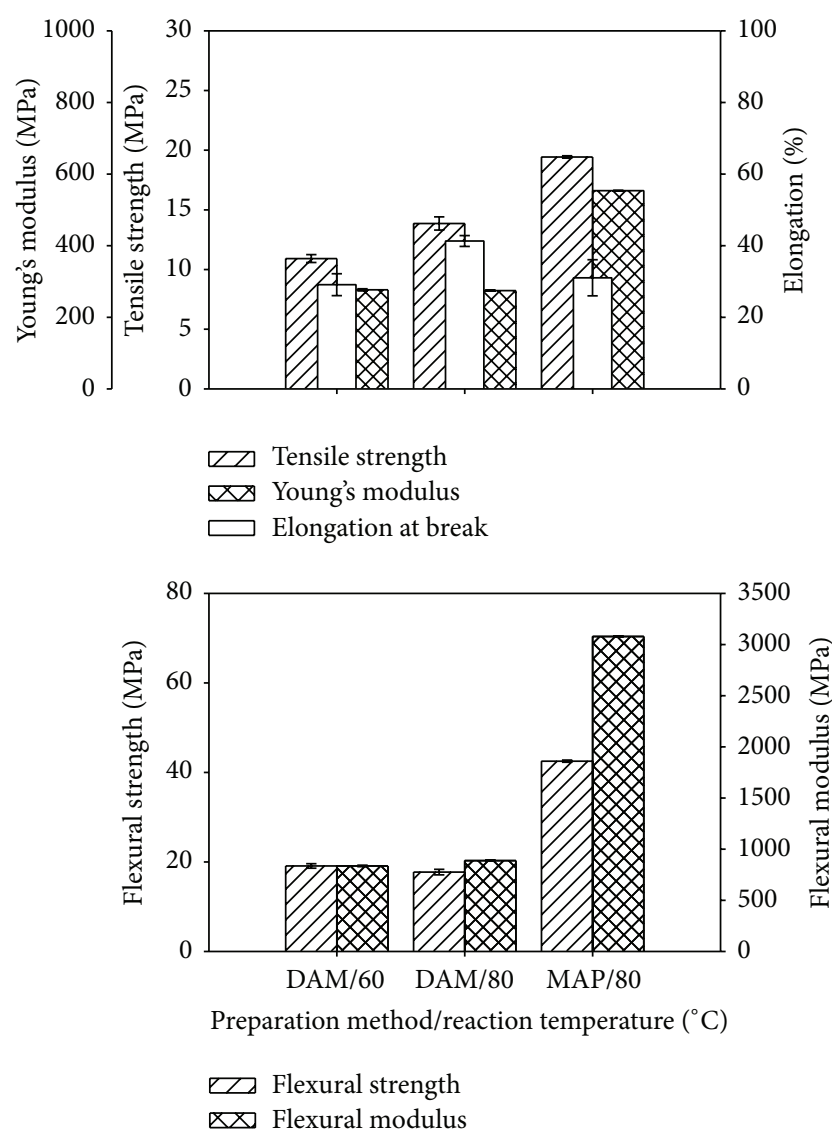

FIGURE 2: Influence of reaction incubation temperatures administered for $1200 \mathrm{~min}$ on the mechanical properties of LC. DAM designates the direct application method for applying IL to dry LC components; MPM indicates premixing matrix materials together with IL and then sandwiching this mixture between burlap layers.

soaked in $30 \mathrm{~min}$ at $25^{\circ} \mathrm{C}$. In addition, we found it important to press the final $\mathrm{LC}$ to compress the components, reduce air spaces, and extrude excess water. LCs that were not pressed were physically weaker and exhibited much lower mechanical properties than pressed LCs.

The influence of incubation temperature on the mechanical properties was explored by incubating LCs at $1200 \mathrm{~min}$ at 60 and $80^{\circ} \mathrm{C}$ followed by mechanical properties testing. Employment of $80^{\circ} \mathrm{C}$ versus $60^{\circ} \mathrm{C}$ improved the $\sigma_{u}$ and $\% \mathrm{El}$ values by $27 \%$ and $42 \%$, respectively, but it had little effect on the stiffness $(E), \sigma_{\mathrm{fm}}$, or $E_{b}$ values. The MPM (premixing the cotton and SEW with IL before sandwiching this mixture between the burlap layers) resulted in an LC with generally better mechanical values compared to LC prepared by the DAM of IL application (Figure 2). LCs prepared by MPM exhibited $\sigma_{u}, E, \sigma_{\mathrm{fm}}$, and $E_{b}$ values that were $+40,+102$, +140 , and $+247 \%$ higher than LCs prepared by the DAM. LCs prepared by MPM exhibited a decrease of $25 \%$ in $\% \mathrm{El}$ values compared to LCs prepared by DAM. As seen in Figure 3, greater integration of the matrix with the burlap bag reinforcement fibers occurs in the LCs utilizing the MPM versus the DAM. LCs produced via the DAM clearly shows the outline of the original burlap bag weave (Figure 3(a)), 


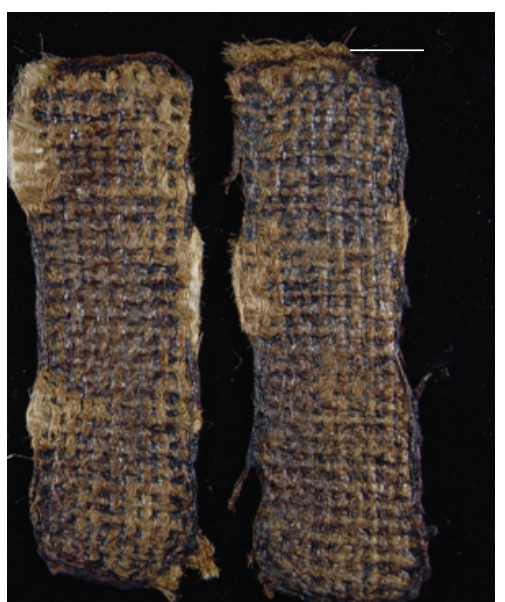

(a)

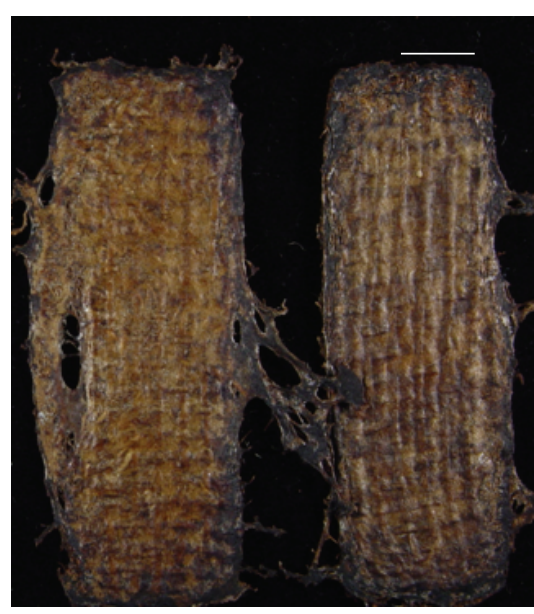

(b)

FIGURE 3: Examples of LCs employing the burlap bag weave fabricated using different preparation procedures. (a) LC obtained from the DAM. (b) LC obtained from MPM. Bar equals $12 \mathrm{~mm}$.

while the MPM method shows a covering of the weave by the matrix materials (Figure 3(b)).

3.2. Influence of Reinforcement Types and Weaves. The influence of the reinforcement medium was investigated by employing burlap weaves of different strand thicknesses and opening sizes (Table 1; Figure 3). Relatively tight weave reinforcement materials produced an LC which had the lowest overall mechanical values of all the reinforcements tested (Figure 4). Visual examination showed that matrix material did not penetrate well between the openings and predominately coated only the outside portion of the weave. This resulted in an LC that exhibited high elongation values but low tensile and flexural values. Interestingly, the burlap bag weave which had thicker strands $(1 \mathrm{~mm})$, smaller opening sizes $\left(1 \mathrm{~mm}^{2}\right)$, and less openings $\left(15.5 / \mathrm{cm}^{2}\right)$ than the tight weave which had thinner strands $(0.5 \mathrm{~mm})$, larger opening sizes $\left(1.5 \mathrm{~mm}^{2}\right)$, and more openings $\left(23.3 / \mathrm{cm}^{2}\right)$ produced LCs with better mechanical properties. It should be noted that this
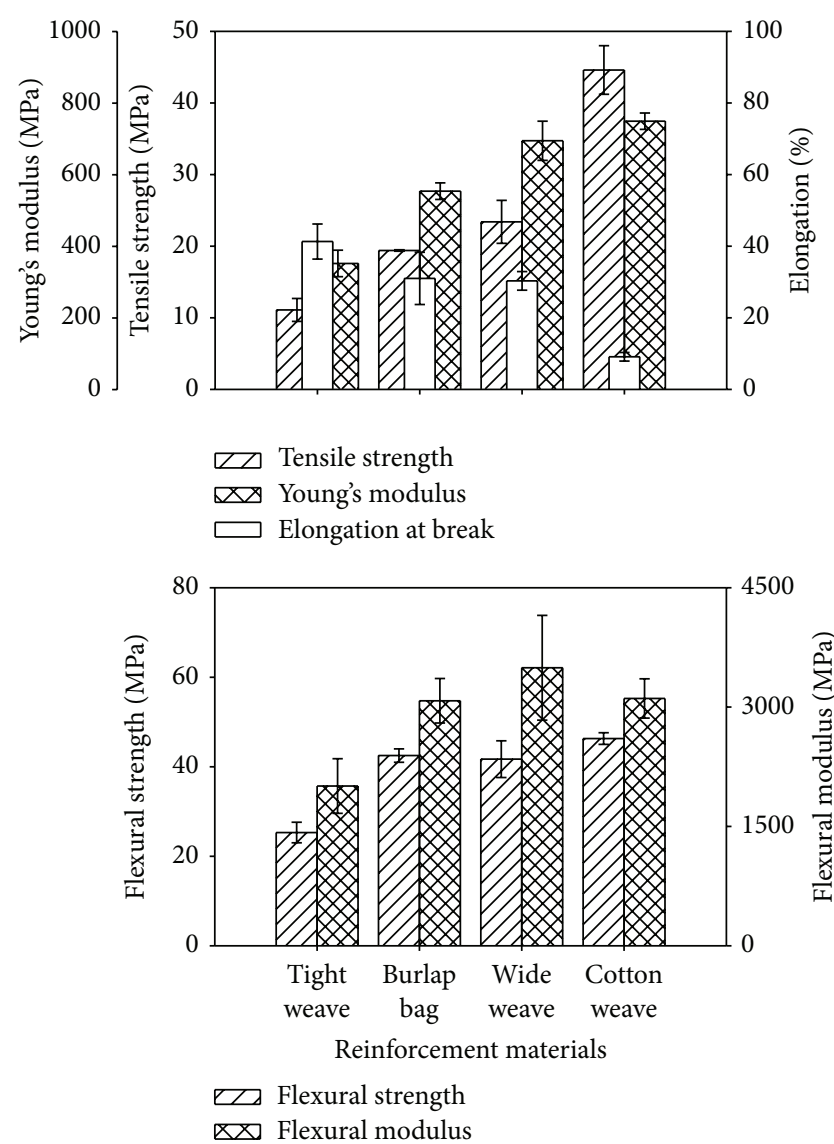

FIGURE 4: Mechanical properties of LC employing various reinforcement weave materials. LCs were prepared using the MPM method with a reaction incubation temperature of $80^{\circ} \mathrm{C}$ followed by $4 \mathrm{hrs}$ of water soaking.

burlap bag weave had more loose fiber protrusions than the tight weave ribbon. This was due to the more highly refined state of manufacturing involved in manufacturing the tight weave burlap ribbon compared to the less expensive burlap bag weave. However, the burlap bag weave/LC exhibited $\sigma_{u}$, $E, \sigma_{\mathrm{fm}}$, and $E_{b}$ values that were $+75,+57,+68$, and $+53 \%$ higher than tight weave/LC. The loose weave burlap/LC and cotton weave/LC exhibited the second best and best mechanical properties of the LCs tested. The cotton weave/LC exhibited the highest $\sigma_{u}$ and $E$ values at $\sim 45 \mathrm{MPa}$ and $\sim 800 \mathrm{MPa}$, respectively (Figure 3). A likely explanation of these results is that increasing the interfacial area of the reinforcement allows for greater access of the matrix material (i.e., loose weave versus tight weave) to produce LCs that had higher mechanical properties.

Figures 5 and 6 graphically compare the mechanical properties of LCs with HDPE and PP by normalizing the LC to known HDPE and PP materials. For example, the $\sigma_{u}, E$, $\% \mathrm{El}, \sigma_{\mathrm{fm}}$, and $E_{b}$ values of the wide weave/LC were 109, 205, 29,149 , and $391 \%$ of that of neat HDPE. Similarly, the $\sigma_{u}$, $E, \% \mathrm{El}, \sigma_{\mathrm{fm}}$, and $E_{b}$ values of the wide weave/LC were 94 , $124,37,95$, and $252 \%$ of that of neat HDPE. These renderings clearly illustrate the influence of reinforced LCs compared 

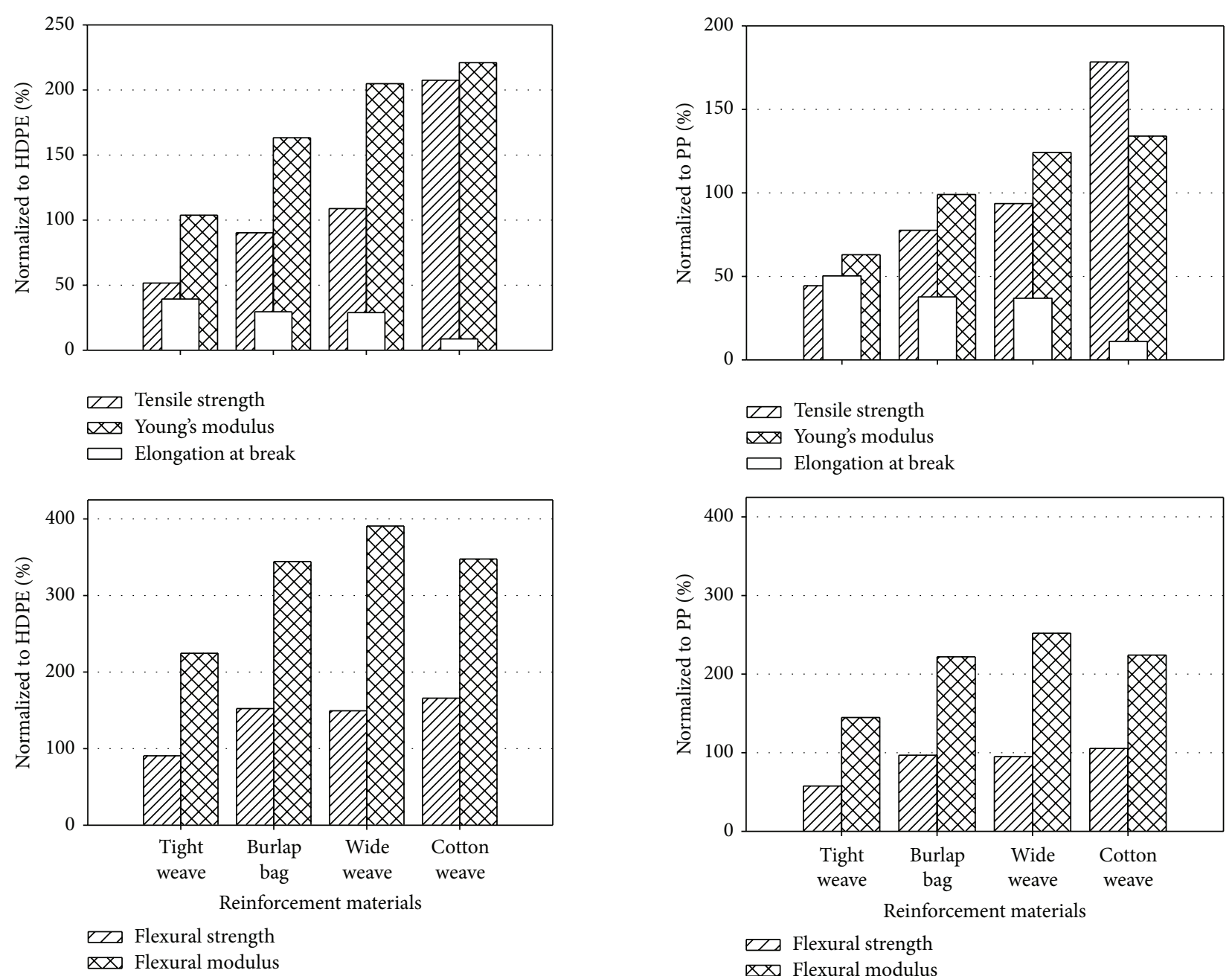

FIGURE 5: Normalized effect of reinforcement materials on the mechanical properties of LCs compared to HDPE.

favorably to commercial polyolefins. It is the contention of the authors that the LCs produced in this study may have merit to compete with polyolefins in certain short term applications. At this time, these LCs should not be considered as durable as polyolefins in terms of their mechanical properties, although they are more biodegradable. However, with appropriate surface functionalization and/or coatings, properties such as water absorption can be significantly altered in these LCs.

\section{Conclusions}

Relatively simple methods to produce LCs were demonstrated using IL. LCs were fabricated from dissimilar components such as cotton, SEW, and burlap fabric using either a direct application of IL solution to prepared dry components or by premixing the matrix materials (cotton and SEW) with IL then applying it to the burlap fabric. Other variables such as fabric weave patterns and solvent incubation time and temperature were found to significantly influence the mechanical properties of LCs generated. The methodologies employed produced LCs on par with synthetic polymers

such as HDPE and PP. There are many remaining questions that need further investigation. As we continue to refine our process methods, optimized LCs will be subjected to chemical (e.g., X-ray diffraction), thermal characterizations and scanning electron microscopy examinations. In addition, studies will be conducted to decrease incubation periods by controlling the amount of adventitious water in substrates and solvent. Finally we are conducting studies to recover and recycle IL-based solvents.

\section{Abbreviations}

WPC: Wood plastic composites

ACC: All-cellulose composites

IL: $\quad$ Ionic liquids

LCs: Lignocellulosic composites

HDPP: High density polyethylene

PP: $\quad$ Polypropylene

EMIMAc: 1-Ethyl-3-methylimidazolium acetate

SEW: Steam exploded wood

ACN: Acetonitrile 
DAM: Direct Application Method

MPM: Matrix Paste Method

E: $\quad$ Tensile modulus

$\sigma_{u}: \quad$ Tensile strength

$\%$ El: Elongation at break

$\sigma_{\text {fm: }}: \quad$ Flexural strength

$E_{b}$ : $\quad$ Flexural modulus of elasticity.

\section{Disclosure}

Mention of a trade names or commercial products in this publication is solely for the purpose of providing specific information and does not imply recommendation or endorsement by the US Department of Agriculture (USDA) or Bradley University.

\section{Conflict of Interests}

The authors declare that there is no conflict of interests regarding the publication of this paper.

\section{Acknowledgments}

The USDA and Bradley University are equal opportunity providers and employers. The authors would like to thank Thomas Elder, USDA-Forest Service Southern Research Station, for providing steam exploded wood fibers. This project was supported, in part, by a Special Emphasis Grant for undergraduate student/faculty collaborative research from Bradley University.

\section{References}

[1] PlasticsEurope.org, “The Plastics Portal," PlasticsEurope Headquarters, Brussels, Belgium, 2014, http://www.plasticseurope .org/what-is-plastic.aspx.

[2] B. Li, J. Asikkala, I. Filpponen, and D. S. Argyropoulos, "Factors affecting wood dissolution and regeneration of ionic liquids," Industrial and Engineering Chemistry Research, vol. 49, no. 5, pp. 2477-2484, 2010.

[3] A. J. J. E. Eerhart, W. J. J. Huijgen, R. J. H. Grisel et al., "Fuels and plastics from lignocellulosic biomass via the furan pathway: a technical analysis," RSC Advances, vol. 4, no. 7, pp. 3536-3549, 2014.

[4] M. Barker and R. Safford, "Industrial uses for crops: markets for bioplastics," Project Report No. 450, HGCA, 2009, http://archive .hgca.com/publications/documents/Bioplastics_web28409.pdf.

[5] M. Gunther, "Can mushrooms replace plastics?" October 2013, EDT, http://www.theguardian.com/sustainable-business/mushrooms-new-plastic-ecovative.

[6] D. K. A. Barnes, F. Galgani, R. C. Thompson, and M. Barlaz, "Accumulation and fragmentation of plastic debris in global environments," Philosophical Transactions B, vol. 364, no. 1526, pp. 1985-1998, 2009.

[7] R. C. Thompson, S. H. Swan, C. J. Moore, and F. S. vom Saal, "Our plastic age," Philosophical Transactions of the Royal Society B: Biological Sciences, vol. 364, no. 1526, pp. 1973-1976, 2009.

[8] Bccresearch.com, Wood-Plastic Composites: Technologies and Global Markets, Report Code: PLS034B, Bccresearch Market
Forecasting, 2011, http://www.bccresearch.com/market-research/ plastics/wood-plastic-composites-tech-markets-pls034b.html.

[9] K. Carlborn and L. M. Matuana, "Functionalization of wood particles through a reactive extrusion process," Journal of Applied Polymer Science, vol. 101, no. 5, pp. 3131-3142, 2006.

[10] J. K. Kim and K. Pal, Recent Advances in the Processing of WoodPlastic Composites, Springer, Berlin, Germany, 2010.

[11] B. Tisserat, L. Reifschneider, R. H. O’Kuru, and V. L. Finkenstadt, "Mechanical and thermal properties of high density polyethylene-dried distillers grains with solubles composites," BioResources, vol. 8, no. 1, pp. 59-75, 2013.

[12] B. Tisserat, L. Reifschneider, D. Grewell, and G. Srinivasan, "Effect of particle size, coupling agent and DDGS additions on Paulownia wood polypropylene composites," Journal of Reinforced Plastics \& Composites, vol. 33, no. 14, pp. 1279-1293, 2014.

[13] D. Fisher, "Societal cost of litter is largely hidden," ecoRInews, Environmental news for southern New England, 2012, http:// www.ecori.org/pollution-contamination/2012/2/2/societal-costof-litter-is-largely-hidden.html.

[14] U.S. Environmental Protection Agency, "Marine debris in North Pacific, a summary of existing information and identification of data gaps," Tech. Rep. US EPA-909-R-11-006, 2011.

[15] T. Nishino, I. Matsuda, and K. Hirao, "All-cellulose composite," Macromolecules, vol. 37, no. 20, pp. 7683-7687, 2004.

[16] T. Huber, J. Müssig, O. Curnow, S. Pang, S. Bickerton, and M. P. Staiger, "A critical review of all-cellulose composites," Journal of Materials Science, vol. 47, no. 3, pp. 1171-1186, 2012.

[17] T. Huber, S. Pang, and M. P. Staiger, "All-cellulose composite laminates," Composites Part A, vol. 43, no. 10, pp. 1738-1745, 2012.

[18] B. J. C. Duchemin, M. P. Staiger, N. Tucker, and R. H. Newman, "Aerocellulose based on all-cellulose composites," Journal of Applied Polymer Science, vol. 115, no. 1, pp. 216-221, 2010.

[19] B. J. C. Duchemin, A. P. Mathew, and K. Oksman, "All-cellulose composites by partial dissolution in the ionic liquid 1-butyl3-methylimidazolium chloride," Composites A: Applied Science and Manufacturing, vol. 40, no. 12, pp. 2031-2037, 2009.

[20] W. Gindl-Altmutter, J. Keckes, J. Plackner, F. Liebner, K. Englund, and M.-P. Laborie, "All-cellulose composites prepared from flax and lyocell fibres compared to epoxy-matrix composites," Composites Science and Technology, vol. 72, no. 11, pp. 13041309, 2012.

[21] L. M. Haverhals, W. M. Reichert, H. C. de Long, and P. C. Trulove, "Natural fiber welding," Macromolecular Materials and Engineering, vol. 295, no. 5, pp. 425-430, 2010.

[22] Q. Zhao, R. C. M. Yam, B. Zhang, Y. Yang, X. Cheng, and R. K. Y. Li, "Novel all-cellulose ecocomposites prepared in ionic liquids," Cellulose, vol. 16, no. 2, pp. 217-226, 2009.

[23] I. Kilpeläinen, H. Xie, A. King, M. Granstrom, S. Heikkinen, and D. S. Argyropoulos, "Dissolution of wood in ionic liquids," Journal of Agricultural and Food Chemistry, vol. 55, no. 22, pp. 9142-9148, 2007.

[24] A. Demirbas, "Competitive liquid biofuels from biomass," Applied Energy, vol. 88, no. 1, pp. 17-28, 2011.

[25] P. S. Nigam and A. Singh, "Production of liquid biofuels from renewable resources," Progress in Energy and Combustion Science, vol. 37, no. 1, pp. 52-68, 2011.

[26] H. Xie, I. Kilpeläinen, A. King, T. Leskinen, P. Järvi, and D. S. Argyropoulos, "Opportunities with wood dissolved in ionic liquids," in Cellulose Solvents: For Analysis, Shaping and Chemical Modification, T. F. Liebert, T. J. Heinze, and K. J. Edgar, 
Eds., vol. 1033 of ACS Symposium Series, chapter 19, pp. 343-363, ACS, Washington, DC, USA, 2010.

[27] K. Shill, S. Padmanabhan, Q. Xin, J. M. Prausnitz, D. S. Clark, and H. W. Blanch, "Ionic liquid pretreatment of cellulosic biomass: enzymatic hydrolysis and ionic liquid recycle," Biotechnology and Bioengineering, vol. 108, no. 3, pp. 511-520, 2011.

[28] J. Luo, M. Cai, and T. Gu, "Pretreatment of lignocellulosic biomass using green ionic liquids," in Green Biomass Pretreatment for Biofuels Production, T. Gu, Ed., SpringerBriefs in Molecular Science, pp. 127-153, Springer Netherlands, 2013.

[29] L. M. Haverhals, L. M. Nevin, M. P. Foley, E. K. Brown, H. C. De Long, and P. C. Trulove, "Fluorescence monitoring of ionic liquid-facilitated biopolymer mobilization and reorganization," Chemical Communications, vol. 48, no. 51, pp. 6417-6419, 2012.

[30] L. M. Haverhals, H. M. Sulpizio, Z. A. Fayos et al., "Process variables that control natural fiber welding: time, temperature, and amount of ionic liquid," Cellulose, vol. 19, no. 1, pp. 13-22, 2012.

[31] L. M. Haverhals, M. P. Foley, E. K. Brown et al., "Ionic liquidbased solvents for natural fiber welding," ECS Transactions, vol. 50, no. 11, pp. 603-613, 2013.

[32] R. Rinaldi, "Instantaneous dissolution of cellulose in organic electrolyte solutions," Chemical Communications, vol. 47, no. 1 , pp. 511-513, 2011.

[33] L. K. J. Hauru, M. Hummel, A. W. T. King, I. Kilpeläinen, and H. Sixta, "Role of solvent parameters in the regeneration of cellulose from ionic liquid solutions," Biomacromolecules, vol. 13, no. 9, pp. 2896-2905, 2012. 

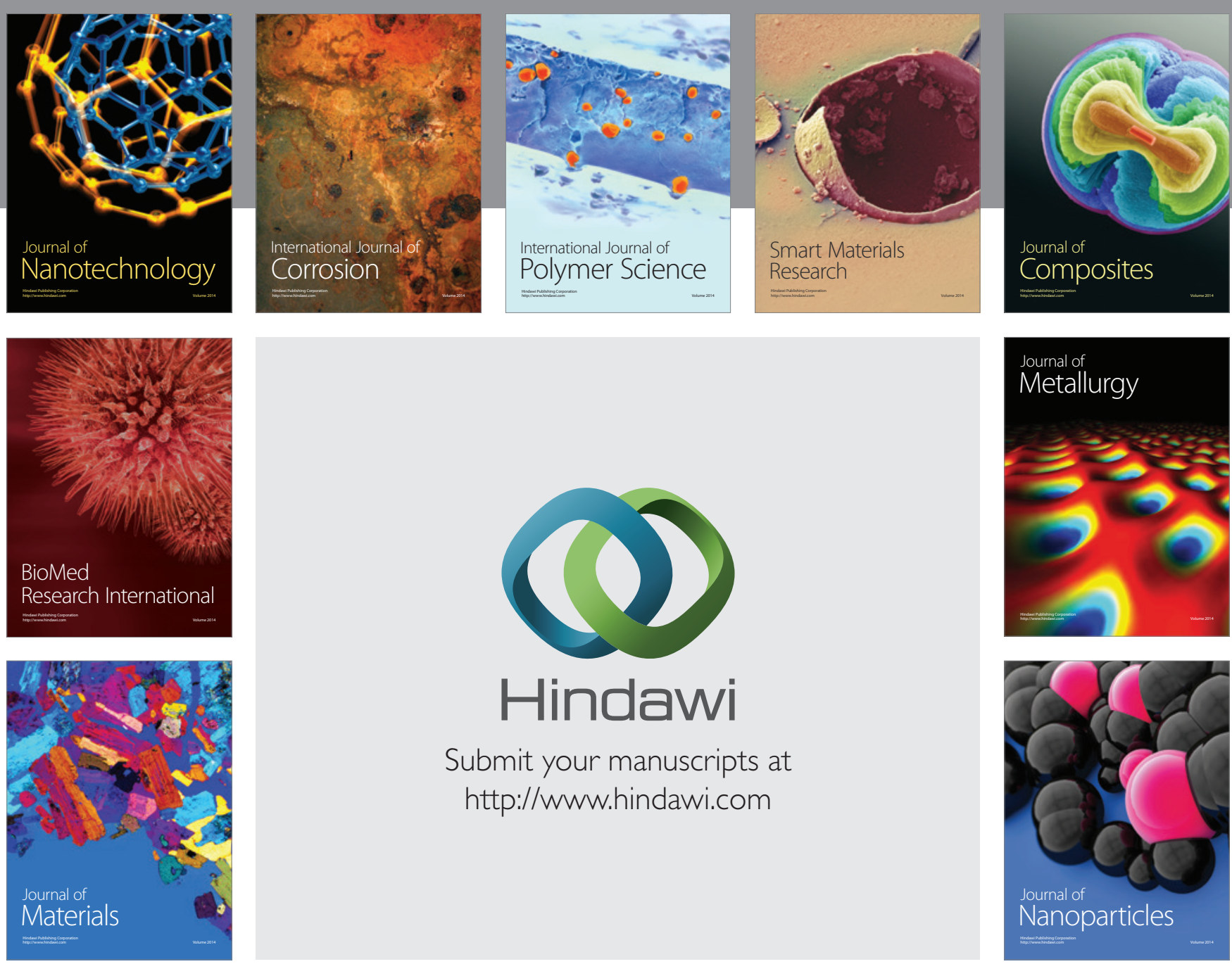

Submit your manuscripts at http://www.hindawi.com
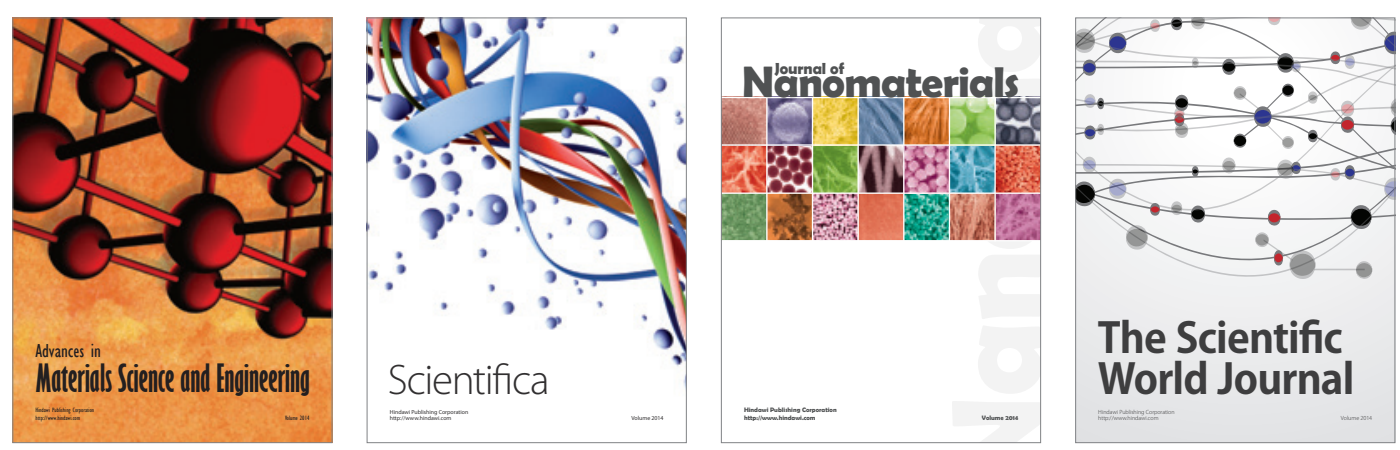

\section{The Scientific World Journal}
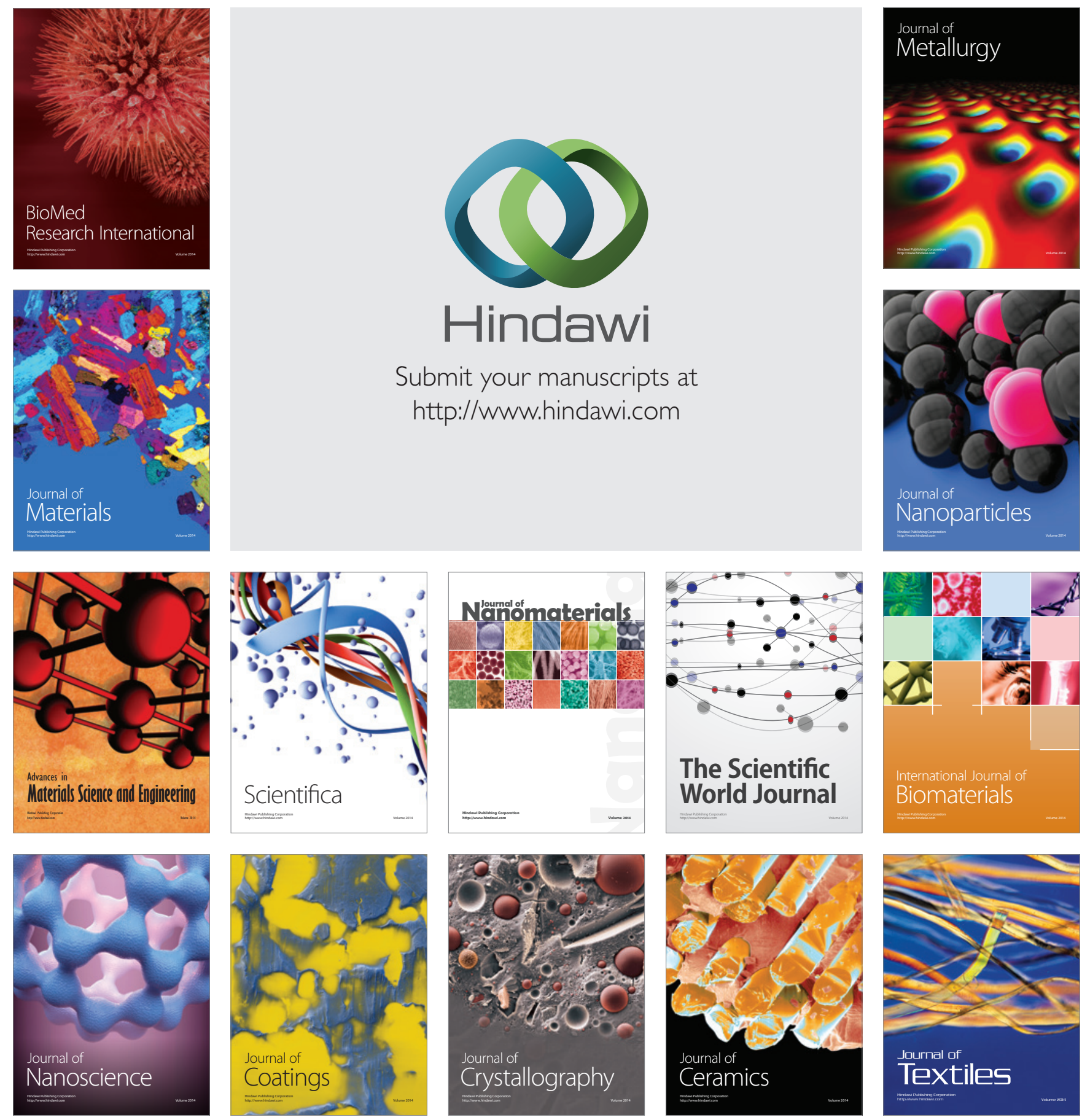